\title{
Evaluation of the effects of a supplementary diet containing chicken comb extract on symptoms and cartilage metabolism in patients with knee osteoarthritis
}

\author{
ISAO NAGAOKA ${ }^{1}$, KUNIHIRO NABESHIMA $^{3}$, SAYA MURAKAMI ${ }^{3}$, TETSURO YAMAMOTO ${ }^{2}$, \\ KEITA WATANABE ${ }^{4}$, AKIHITO TOMONAGA ${ }^{5}$ and HIDEYO YAMAGUCHI ${ }^{2}$ \\ ${ }^{1}$ Department of Host Defense and Biochemical Research, Juntendo University, Graduate School of Medicine, \\ Tokyo; ${ }^{2}$ Total Technological Consultant Co., Ltd., Tokyo; ${ }^{3}$ Everlife Co., Ltd., Fukuoka; \\ ${ }^{4}$ Kitashinyokohama Orthopedic Surgery, Kanagawa; ${ }^{5}$ Tana Orthopedic Surgery, Kanagawa, Japan
}

Received April 21,2010; Accepted June 17, 2010

DOI: $10.3892 / \mathrm{etm} .2010 .114$

\begin{abstract}
We aimed to investigate whether a supplementary diet containing chicken comb extract (CCE) rich in hyaluronic acid (HA) has an effect on pain and other symptoms, as well as cartilage type II collagen (CII) metabolism in patients with knee osteoarthritis (OA). A randomized double-blind placebo-controlled study was conducted in 43 subjects with knee OA (Kellgren/Lawrence grade, mainly 1-2) comprising 22 patients receiving concurrent exercise therapy (ET) and 21 without ET (referred as ET-receivers and ET-unreceivers, respectively). Subjects were randomized to a CCE-containing diet (active diet) group administered a dose of $1,800 \mathrm{mg} /$ day (containing $630 \mathrm{mg}$ of CCE and approximately $60 \mathrm{mg}$ of HA) and a placebo group, and the intervention was continued for 16 weeks. Symptomatic efficacy was evaluated based on the Japanese Orthopaedic Association clinical trials response criteria (JOA response criteria) and Visual analog scales (VAS) before (baseline) and during the intervention. To further examine its effect on CII metabolism, the levels of two degradation biomarkers (CTX-II and C2C) and one synthesis biomarker (CPII) were measured using urine or serum samples. Nineteen subjects (10 ET-receivers and 9 ET-unreceivers) in the active diet group and 21 subjects (10 ET-receivers and 11 ET-unreceivers) in the placebo group were finally included in the study. Compared to the baseline, subscale scores of the JOA response criteria, i.e., 'pain/walking function', 'pain/step-up and -down function' and 'aggregate total symptoms' were more intensely improved in the active diet group than in the placebo group. Moreover, subgroup analyses of ET-receivers and ET-unreceivers indicated that significant
\end{abstract}

Correspondence to: Dr Isao Nagaoka, Department of Host Defense and Biochemical Research, Juntendo University, Graduate School of Medicine, 2-1-1 Hongo, Bunkyo-ku, Tokyo 113-8421, Japan E-mail: nagaokai@juntendo.ac.jp

Key words: supplementary diet, hyaluronic acid, osteoarthritis, type II collagen, biomarker improvements were restricted to ET-receivers of the active diet group. Furthermore, VAS assessment indicated that the 'pain on pressing' subscale was significantly improved in ET-receivers of the active diet group. In addition, analysis of CII biomarkers revealed that serum $\mathrm{C} 2 \mathrm{C}$ and CPII levels, but not the urinary CTX-II level, were increased in the active diet group. Notably, both urinary CTX-II/serum CPII and serum $\mathrm{C} 2 \mathrm{C} /$ serum CPII ratios were reduced in the active diet group (particularly ET-unreceivers), suggesting that CII synthesis was relatively increased compared to CII degradation in the active diet group. Finally, no diet-related side effects were observed. The CCE-containing diet is likely to be effective in relieving symptoms in patients with knee OA. In addition, it has the potential to improve the balance of CII degradation/ synthesis in knee OA.

\section{Introduction}

Osteoarthritis (OA) is an articular disorder causing pain and increasing movement limitations due to the progressive destruction of articular cartilage. OA is known as the most common joint disease in developed countries, including Japan, and is highly prevalent among the elderly, resulting in one of the leading causes of chronic disability. Moreover, $\mathrm{OA}$ is recognized to interfere with several aspects of an individual's life, including not only physical functions but also social activities, economical burdens and psychological wellbeing (1). Knee OA, one of the most common forms of OA, is estimated to affect up to 30 million people in Japan, who are mostly over 50 years of age (2).

Current treatments of knee OA include surgical treatment, ranging from arthroscopy to total knee replacement, and pharmacological treatments, with adjunctive exercise and/or physical therapies. Since there is no curative therapy for OA, the most pressing need for patients with OA is non-operative care that helps to relieve symptoms and suppresses disease progression (3). Pharmacological treatments of OA can be divided into two groups: symptom-modifying and diseasemodifying (chondroprotective) drugs. Symptom-modifying drugs include simple analgesics (e.g., acetaminophen) and 
nonsteroidal anti-inflammatory drugs (NSAIDs). Although NSAIDs are most widely used, the risk of peptic ulcer, renal hypertension and hemorrhage is high in elderly patients taking NSAIDs. Moreover, certain NSAIDs are shown to have negative effects on cartilage metabolism and to accelerate the progression of OA in humans (4).

Adverse effects of NSAIDs have prompted the screening and development of novel drugs (i.e., disease-modifying drugs) that could interfere with disease progression and protect and regenerate cartilage in OA. Although no drug has yet been identified in the second category, various natural compounds, such as glucosamine and chondroitin sulfate, have been investigated as promising candidates (5).

Hyaluronic acid (HA) is a glycosaminoglycan with a repeating unit of $\mathrm{D}$-glucuronic acid and $\mathrm{N}$-acetylglucosamine. It is a constituent of synovial fluid and cartilage matrix and contributes to lubricating articular cartilage as well as synthesizing proteoglycans. HA content in the synovial fluid is reduced, and the viscoelastic properties of the fluid are compromised in knee OA, thereby increasing susceptibility of cartilage to injury. Thus, intra-articular administration (viscosupplementation) of HA has been widely accepted for improving pain and articular function in knee OA $(6,7)$. Regarding HA administration, several clinical trials have indicated that the pain-relieving effect of intra-articular HA persists for substantially longer than its half-life within the injected joint $(8,9)$, suggesting that HA possesses not only symptom-modifying, but also disease-modifying activity $(5,10,11)$. This is further supported by the experimental findings that HA directly stimulates articular chondrocytes to proliferate and synthesize sulfated glycosaminoglycan and type II collagen (CII) $(12,13)$.

However, intra-articular HA injection causes deleterious complications at the injection site and discomfort associated with repeated injections (14). Moreover, an animal experiment found that orally administered HA was detected in the circulating blood of rats (15). These findings led us to investigate the symptom- and/or disease-modifying effects of oral $\mathrm{HA}$ in patients with knee OA. For this purpose, we evaluated a commercially available supplementary diet containing a chicken comb extract (CCE) and other nutrients $\left(\right.$ Kojun $\left.^{\circledR}\right)$. Previously, Hatayama et al conducted a randomized, placebocontrolled study in 29 patients with knee pain and revealed that a 2-week ingestion of this CCE-containing diet $(1,800 \mathrm{mg} /$ day containing $630 \mathrm{mg}$ of CCE and $60 \mathrm{mg}$ of HA) significantly improved pain and discomfort in the affected knee (16).

The present study was undertaken, not only to confirm the symptom-modifying effect of the CCE-containing product (active diet), but also to investigate its potential disease-modifying effect in patients with knee OA. The most established method by which to evaluate joint damage in knee $\mathrm{OA}$ is the joint space width (JSW) measurement using plain $\mathrm{X}$-rays. However, since changes in JSW are small, at least one year and preferably two years are usually necessary to accurately assess the progression of joint damage or the effect of disease-modifying treatment (17). Therefore, for efficient monitoring, more sensitive and feasible methods must be developed. Several biochemical markers (biomarkers) have been established and have greater reliability and sensitivity than radiographs for the early diagnosis or prognosis of OA
(18). Furthermore, such biomarkers are useful for evaluating the actions of disease-modifying drugs as they specifically reflect changes in the metabolism of cartilage and related tissues (19). Although increasing numbers of OA-related biomarkers are available, we utilized three cartilage biomarkers specific for CII metabolism, including two CII degradation biomarkers, C-terminal cross-linked telopeptide of CII (CTX-II) and CII C2C neopeptide (C2C), and one CII synthesis biomarker, C-terminal propeptide of CII procollagen (CPII), since abnormalities in CII metabolism play a key role in the pathogenesis of OA (20). Furthermore, it is suggested that OA develops from an imbalance in the synthesis and degradation of cartilage CII, and that the ratio of a CII degradation biomarker to a synthesis biomarker predicts more precisely the progression of OA than individual biomarkers (21,22). Thus, we also assessed the CTX-II/CPII and C2C/ $\mathrm{CPII}$ ratios as parameters for $\mathrm{CII}$ metabolism.

\section{Materials and methods}

Study design. A prospective randomized double-blind placebocontrolled, parallel-group comparative study was designed to assess the actions of the active diet and placebo on both symptoms and CII metabolism in adult subjects with knee OA. The safety of the active diet was also evaluated. The study was performed from June 2008 to December 2008 and involved two clinical service organization centers in Japan. The study protocol was approved by the local ethics committee and was conducted in accordance with the principles of the amended Declaration of Helsinki and 'Ethical Guidelines for Epidemiological Research'. Written informed consent was obtained from all participants prior to their enrollment in the study. The entire study period consisted of a 16 -week intervention phase and a preceding 8-week screening phase. Subjects were screened at a baseline visit by a physical examination, a knee radiograph according to a standardized method, a symptom questionnaire and routine laboratory tests. After the start of intervention, medical examinations and laboratory tests were performed at weeks 4, 8, 12 and 16 for the enrolled subjects.

Subjects. Male and female Japanese subjects, 40-85 years of age, diagnosed with knee OA with Kellgren/Lawrence (K/L) grades 0-3 (mainly 1-2) were enrolled. The entire subject populations consisted of almost equal numbers of subjects undergoing concurrent exercise therapy (ET, including resistance exercise, sit-to-stand exercise, aerobic/walking exercise and water/pool walking exercise) and without ET. The former subjects were referred to as ET-receivers and the latter as ET-unreceivers, and both classes of subjects were almost equally distributed between the active diet and placebo groups. Subjects with bilateral diagnosed knee OA were asked to specify their worse knee at baseline, and this knee was evaluated throughout the study period. Exclusion criteria were: any inflammatory condition of bone or cartilage; previous surgical treatment of knee joint(s) or its necessity; complication(s) necessary for hospitalization and surgical treatment; known allergy to chicken or some constituent of the active diet; participation in any clinical trial; pregnant women; nursing mothers or women with child-bearing potential; treatment 
with intra-articular HA within 2 weeks or corticosteroids within 3 months in the target joint; use of health foods, including constituents with knee pain-relieving potential (e.g., glucosamine, chondroitin sulfate and HA) within 2 weeks; and the presence of any clinically significant condition judged by the medical investigator to preclude the subject's inclusion in the study.

Intervention and subject assignment. The active diet is manufactured in the form of a 300-mg pill. Its ingredients are: $105 \mathrm{mg}$ of CCE, $10 \mathrm{mg}$ of propolis extract, $4.9 \mathrm{mg}$ of xanthooligo-sugar, $5 \mathrm{mg}$ of vitamin B1, $5 \mathrm{mg}$ of vitamin B6, $0.1 \mathrm{mg}$ of vitamin B12, $2.5 \mathrm{mg}$ of vitamin E, $2 \mathrm{mg}$ of ferric pyrophosphate, $20 \mathrm{mg}$ of calcium lactate and $140 \mathrm{mg}$ of vehicle (comprising crystalline cellulose, dextrin and fatty acid sugar esters).

Each population of 22 ET-receivers and 21 ET-unreceivers (8 males and 35 females in total) was randomly assigned to receive 6 pills $(1,800 \mathrm{mg})$ of the active diet or dummy placebo containing only vehicle (crystalline cellulose, dextrin and fatty acid sugar esters). The daily dose of the active diet used in the present study was determined on the basis of the results obtained in our preceding study (16). Adherence to the intervention was evaluated based on the doses recorded in the study diary, and a value $<80 \%$ was considered a protocol violation.

Evaluation of efficacy and safety. Symptomatic changes were assessed according to scores of the Japanese Orthopaedic Association clinical trials response criteria (JOA response criteria) for articular disorders of the knee and visual analog scales (VAS). Questionnaires were collected at baseline and at weeks 4, 8, 12 and 16 after the initiation of intervention. Assessments were performed at each time point.

In this study, five subscales of JOA response criteria closely related to knee OA were selected for the assessment: i) pain/walking function; ii) pain/step-up and -down function; iii) joint flexion/stiffness; iv) swelling; and v) aggregated total symptoms. The former 4 subscales were rated from 0 to 30 , from 0 to 25 , from 0 to 35 and from 0 to 10 , respectively. The maximum value indicated no symptoms or functional disability, and a score of 0 indicated a condition resulting in extreme difficulty to perform daily living tasks. The sum of the scores for these four subscales represented the scores for the fifth subscale (aggregate total symptoms).

Three subscales of 100-mm VAS were used to measure pain in the target knee: i) pain at rest; ii) pain on moving; and iii) pain on pressing. Each VAS subscale was scored from 0 to 100 , where 0 indicated no pain and 100 indicated intense pain. Since the present study aimed to evaluate the intervention diet for its pain relief and/or physical improvement capabilities, only knee joints with a VAS score $\geq 40$ were used as the target.

Serum and urine samples were collected at baseline and at weeks 8,12 and 16 during the intervention, and were stored at $-70^{\circ} \mathrm{C}$ until use. When the study was completed, the samples were analyzed for CII degradation biomarkers (CTX-II and $\mathrm{C} 2 \mathrm{C}$ ) and a CII synthesis biomarker (CPII) to assess changes in cartilage metabolism. Urinary CTX-II (uCTX-II), serum $\mathrm{C} 2 \mathrm{C}(\mathrm{sC} 2 \mathrm{C}$ ) and serum CPII (sCPII) were measured using Urine CartiLaPs EIA (Immunodiagnostic Systems Ltd.), Collagen Type II ELISA (IBEX Pharmaceuticals Inc.) and
Procollagen II C Propeptide ELISA (IBEX Pharmaceuticals Inc.). The level of uCTX-II was corrected for urinary creatinine (Cr) measured by a standard colorimetric assay and expressed as $\mathrm{ng} / \mathrm{mmol} \mathrm{Cr}$. The changes from baseline of uCTX-II, sC2C and sCPII, as well as uCTX-II/sCPII and sC2C/sCPII ratios, were compared between the active diet and placebo groups.

Tolerability and safety were assessed throughout the study on the basis of the incidence and severity of diet-related adverse events (side effects) as well as abnormal changes in blood pressure, pulse rate and laboratory tests, including hematology, biochemical profile and urinalysis. In addition, to examine whether a 16-week ingestion of the active diet influenced the pharmakokinetics of HA, the serum HA (sHA) levels at baseline and week 16 were compared in both the active diet and placebo groups.

Statistical analysis. Values are expressed as the mean \pm SD. Baseline characteristics of the entire subject populations, ET-receivers and ET-unreceivers were compared between the two groups by the Student's t-test for continuous variables and by the Mann-Whitney U test for category variables. Symptomatic scores and biomarker levels during the intervention were compared to baseline values by the Student's t-test (for quantitative variables) and the Wilcoxon's signed rank test (for qualitative variables). Comparisons between the groups were made by the Student's t-test (for quantitative variables). P-values $<0.05$ were considered significant.

\section{Results}

Baseline characteristics. Table I presents the baseline characteristics of all subjects in the active diet and placebo groups together with those of ET-receivers and ET-unreceivers. Of the 43 enrolled subjects ( 8 men and 35 women), 21 subjects comprising 11 ET-receivers and 10 ET-unreceivers were assigned to the active diet, and 22 subjects comprising 11 each of the ET-receivers and ET-unreceivers were assigned to the placebo group. The baseline characteristics included demographic characteristics (age and male/female ratio), physiological characteristics (height, body weight, body mass index, systolic/diastolic blood pressures and pulse rate), JOA response criteria score for 'aggregate total symptoms', three pain subscale scores of VAS, subject distribution on the $\mathrm{K} / \mathrm{L}$ grade, levels of CII metabolism biomarkers (uCTX-II, sC2C and sCPII) and serum HA (sHA). No significant differences were observed between the active diet and placebo groups in most of these variables, except sCPII and sHA.

The sCPII levels were significantly higher in the subjects of the placebo group $(1,638 \pm 624 \mathrm{ng} / \mathrm{ml})$ than in those of the active diet group $(1,146 \pm 404 \mathrm{ng} / \mathrm{ml}, \mathrm{P}<0.01)$. Similarly, sCPII levels were significantly higher in ET-unreceivers of the placebo group and in those of the active diet group $(1,690 \pm 393$ vs. $1,007 \pm 179 \mathrm{ng} / \mathrm{ml}, \mathrm{P}<0.01)$. Although the two groups (active diet and placebo) were not balanced for sCPII, this biomarker was regarded as an evaluable parameter in this study, since no relationship was observed between the sCPII level and the severity of symptoms or radiographies of knee OA. Furthermore, there was no significant difference between the two groups in the levels of two other CII metabolism biomarkers, uCTX-II and $\mathrm{sC} 2 \mathrm{C}$. 
Table I. Baseline characteristics of the study populations in the active diet and placebo groups ${ }^{\mathrm{a}}$.

\begin{tabular}{|c|c|c|c|c|c|c|}
\hline \multirow[t]{2}{*}{ Variables } & \multicolumn{2}{|c|}{ All subjects } & \multicolumn{2}{|c|}{ ET-receivers $^{b}$} & \multicolumn{2}{|c|}{ ET-unreceivers $^{c}$} \\
\hline & $\begin{array}{l}\text { Active diet } \\
\quad(\mathrm{n}=21)\end{array}$ & $\begin{array}{c}\text { Placebo } \\
(\mathrm{n}=22)\end{array}$ & $\begin{array}{l}\text { Active diet } \\
\quad(\mathrm{n}=11)\end{array}$ & $\begin{array}{c}\text { Placebo } \\
(\mathrm{n}=11)\end{array}$ & $\begin{array}{l}\text { Active diet } \\
\quad(\mathrm{n}=10)\end{array}$ & $\begin{array}{l}\text { Placebo } \\
(\mathrm{n}=11)\end{array}$ \\
\hline Age (years) & $62.4 \pm 12.5$ & $63.3 \pm 9.5$ & $66.9 \pm 14.3$ & $65.4 \pm 11.1$ & $57.5 \pm 8.2$ & $61.2 \pm 7.5$ \\
\hline $\begin{array}{l}\text { Male:Female } \\
\text { (no. of subjects) }\end{array}$ & $4: 17$ & $4: 18$ & $3: 8$ & $4: 7$ & $1: 9$ & $0: 11$ \\
\hline Height (cm) & $155.0 \pm 8.5$ & $157.1 \pm 6.2$ & $155.0 \pm 8.6$ & $159.5 \pm 4.7$ & $154.9 \pm 8.8$ & $154.7 \pm 6.8$ \\
\hline Body weight $(\mathrm{kg})$ & $56.2 \pm 8.6$ & $57.1 \pm 8.5$ & $56.3 \pm 10.5$ & $56.3 \pm 5.6$ & $56.1 \pm 6.6$ & $57.9 \pm 10.9$ \\
\hline Body mass index $\left(\mathrm{kg} / \mathrm{m}^{2}\right)$ & $23.3 \pm 3.0$ & $23.3 \pm 3.5$ & $23.5 \pm 3.9$ & $22.5 \pm 1.8$ & $23.0 \pm 1.8$ & $24.0 \pm 4.6$ \\
\hline Systolic blood pressure (mmHg) & $127.8 \pm 16.6$ & $132.0 \pm 17.0$ & $132.9 \pm 17.1$ & $133.1 \pm 18.3$ & $122.2 \pm 14.7$ & $131.0 \pm 16.5$ \\
\hline Diastolic blood pressure $(\mathrm{mmHg})$ & $76.0 \pm 7.8$ & $76.6 \pm 11.2$ & $74.3 \pm 8.3$ & $77.1 \pm 11.5$ & $77.9 \pm 7.1$ & $76.1 \pm 11.4$ \\
\hline Pulse rate (beats/min) & $69.3 \pm 8.2$ & $73.0 \pm 12.7$ & $66.5 \pm 9.4$ & $74.1 \pm 15.5$ & $72.3 \pm 5.6$ & $72.0 \pm 10.0$ \\
\hline $\begin{array}{l}\text { JOA response criteria score } \\
\text { for aggregated total symptoms }\end{array}$ & $87.6 \pm 7.0$ & $88.6 \pm 6.9$ & $87.3 \pm 6.5$ & $85.9 \pm 7.0$ & $88.0 \pm 7.9$ & $91.4 \pm 6.0$ \\
\hline \multicolumn{7}{|l|}{ 100-mm VAS scores } \\
\hline Pain at rest $(\mathrm{mm})$ & $41.7 \pm 21.0$ & $39.1 \pm 20.0$ & $42.1 \pm 15.1$ & $37.1 \pm 17.5$ & $41.2 \pm 26.9$ & $41.0 \pm 23.0$ \\
\hline Pain on moving $(\mathrm{mm})$ & $65.9 \pm 13.5$ & $56.4 \pm 18.8$ & $64.9 \pm 12.9$ & $61.1 \pm 14.8$ & $67.1 \pm 14.8$ & $51.6 \pm 21.7$ \\
\hline Pain on pressing $(\mathrm{mm})$ & $56.2 \pm 21.5$ & $51.5 \pm 19.1$ & $55.7 \pm 23.9$ & $47.5 \pm 15.9$ & $56.7 \pm 19.8$ & $55.4 \pm 22.0$ \\
\hline \multicolumn{7}{|l|}{ Kellgren-Lawrence grade } \\
\hline 0:I:II:III (no. of subjects) & $4: 11: 5: 1$ & 7:7:8:0 & $2: 6: 2: 1$ & $2: 4: 5: 0$ & $2: 5: 3: 0$ & $5: 3: 3: 0$ \\
\hline Urinary CTX-II (ng/mmol Cr) & $384.7 \pm 186.7$ & $353.7 \pm 133.0$ & $364.2 \pm 201.7$ & $359.4 \pm 119.0$ & $409.8 \pm 175.0$ & $348.1 \pm 151.3$ \\
\hline Serum C2C (ng/ml) & $224.8 \pm 37.9$ & $222.1 \pm 21.3$ & $216.1 \pm 40.0$ & $220.3 \pm 24.2$ & $234.4 \pm 34.9$ & $223.8 \pm 19.0$ \\
\hline Serum CPII (ng/ml) & $1,146 \pm 404$ & $1,638 \pm 624^{\mathrm{f}}$ & $1,272 \pm 510$ & $1,587 \pm 811$ & $1,007 \pm 179$ & $1,690 \pm 393^{f}$ \\
\hline Serum HA ${ }^{\mathrm{d}}(\mathrm{ng} / \mathrm{ml})$ & $52.5 \pm 42.0^{\mathrm{f}}$ & $24.2 \pm 16.9$ & $50.8 \pm 28.1^{\mathrm{e}}$ & $23.6 \pm 17.9$ & $54.4 \pm 55.1$ & $24.7 \pm 16.8$ \\
\hline
\end{tabular}

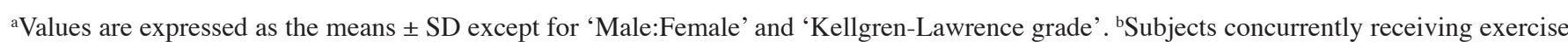
therapy (ET). 'Subjects not receiving any ET. ${ }^{\mathrm{d}}$ Values $<10 \mathrm{ng} / \mathrm{ml}$ were estimated as $10 \mathrm{ng} / \mathrm{ml}$. ${ }^{\mathrm{e}} \mathrm{P}<0.05,{ }^{\mathrm{f}} \mathrm{P}<0.01$ (comparison between the active diet and placebo groups in the study populations of all subjects, ET-receivers and ET-unreceivers).

The concentrations of sHA ranged widely among the entire subjects at baseline. Of the 43 subjects, 10 had values below the detection limit $(10 \mathrm{ng} / \mathrm{ml})$, whereas 2 allotted to the active diet had high values (111 and $155 \mathrm{ng} / \mathrm{ml})$. Thus, the sHA levels for all subjects as well as for ET-receivers in the active diet group were 2-fold higher than those in the placebo group $(\mathrm{P}<0.01$ and $<0.05$, respectively). However, there was no significant change in the concentrations of sHA between baseline and week 16 in the active diet group (data not shown), suggesting that the ingestion of the active diet containing HA had no effect on the sHA level.

Among the 21 subjects in the active diet group, 1 female ET-receiver had her right little toe bone fractured soon after the initiation of intervention and was released from the study on the 3rd day of the intervention. Another female ET-receiver in the active diet group was also removed from the study, since her sHA level was markedly unstable (the value changed from $111 \mathrm{ng} / \mathrm{ml}$ at baseline to $444 \mathrm{ng} / \mathrm{ml}$ at week 16), suggesting that she may have had some abnormalities in HA metabolism. In the placebo group, 1 female ET-receiver experienced gastric discomfort at 2 and 3 days after the initiation of intervention. Although this symptom disappeared on day
4, she voluntarily resigned from the study on the next day. Thus, 19 subjects (9 ET-receivers and 10 ET-unreceivers) in the active diet group and 21 subjects (10 ET-receivers and 11 ET-unreceivers) in the placebo group completed the study. Adherence to active diet and placebo in this study (assessed by pill counts) exceeded $80 \%$.

Assessment based on the JOA response criteria. Table II shows the changes in the five subscale scores of the JOA response criteria during the 16 -week intervention. In the active diet group, three subscale scores, i.e., 'pain/walking function', 'pain/step-up and -down function' and 'aggregate total symptoms', were increased compared to the baseline (indicating clinical improvement) after 8 weeks of intervention $(\mathrm{P}<0.05)$. In the placebo group, these subscale scores were similarly increased; however, the degrees were much smaller than those in the active diet group. By contrast, scores for 'joint flexion/stiffness' and 'swelling' subscales did not essentially change in either of the groups throughout the intervention period. Fig. 1 shows the changes in subscale scores from baseline during the intervention. Notably, "pain/step-up and -down function' and 'aggregate total symptoms' subscale 
Table II. Changes in the five subscale scores of JOA response criteria during intervention for all subjects in the active diet ( $\mathrm{n}=19)$ and placebo $(n=21)$ groups.

\begin{tabular}{|c|c|c|c|c|c|c|}
\hline \multirow[t]{2}{*}{ Subscales } & \multirow[t]{2}{*}{ Group } & \multicolumn{5}{|c|}{ Scores $($ mean $\pm \mathrm{SD})$} \\
\hline & & Baseline & 4 weeks & 8 weeks & 12 weeks & 16 weeks \\
\hline I. Pain/walking function & $\begin{array}{c}\text { Active diet } \\
\text { Placebo }\end{array}$ & $\begin{array}{l}26.3 \pm 4.4 \\
26.0 \pm 4.4\end{array}$ & $\begin{array}{l}27.4 \pm 3.5 \\
26.7 \pm 4.3\end{array}$ & $\begin{array}{l}28.9 \pm 2.7^{\mathrm{a}} \\
26.9 \pm 3.7^{\mathrm{a}}\end{array}$ & $\begin{array}{l}29.2 \pm 2.5^{\mathrm{b}} \\
27.6 \pm 3.4^{\mathrm{a}}\end{array}$ & $\begin{array}{l}29.7 \pm 1.1^{\mathrm{b}} \\
27.9 \pm 3.4^{\mathrm{a}}\end{array}$ \\
\hline II. Pain/step-up and -down function & $\begin{array}{l}\text { Active diet } \\
\text { Placebo }\end{array}$ & $\begin{array}{l}19.5 \pm 1.6 \\
19.5 \pm 1.5\end{array}$ & $\begin{array}{l}20.3 \pm 1.1 \\
20.0 \pm 2.2\end{array}$ & $\begin{array}{l}20.3 \pm 2.0 \\
20.0 \pm 2.2\end{array}$ & $\begin{array}{l}21.1 \pm 2.1^{\mathrm{a}} \\
20.0 \pm 2.2\end{array}$ & $\begin{array}{l}22.4 \pm 2.6^{b} \\
20.7 \pm 2.9^{*}\end{array}$ \\
\hline III. Joint flexion/stiffness & $\begin{array}{l}\text { Active diet } \\
\text { Placebo }\end{array}$ & $\begin{array}{l}32.6 \pm 3.1 \\
33.3 \pm 2.9\end{array}$ & $\begin{array}{l}32.6 \pm 3.1 \\
33.3 \pm 2.9\end{array}$ & $\begin{array}{l}32.6 \pm 3.1 \\
33.3 \pm 2.9\end{array}$ & $\begin{array}{l}32.9 \pm 3.0 \\
33.3 \pm 2.9\end{array}$ & $\begin{array}{l}33.2 \pm 3.0 \\
33.3 \pm 2.9\end{array}$ \\
\hline IV. Swelling & $\begin{array}{l}\text { Active diet } \\
\text { Placebo }\end{array}$ & $\begin{array}{r}9.7 \pm 1.1 \\
10.0 \pm 0.0\end{array}$ & $\begin{array}{l}10.0 \pm 0.0 \\
10.0 \pm 0.0\end{array}$ & $\begin{array}{l}10.0 \pm 0.0 \\
10.0 \pm 0.0\end{array}$ & $\begin{array}{l}10.0 \pm 0.0 \\
10.0 \pm 0.0\end{array}$ & $\begin{array}{l}10.0 \pm 0.0 \\
10.0 \pm 0.0\end{array}$ \\
\hline V. Aggregate total symptoms & $\begin{array}{c}\text { Active diet } \\
\text { Placebo }\end{array}$ & $\begin{array}{l}88.2 \pm 6.7 \\
88.8 \pm 7.1\end{array}$ & $\begin{array}{l}91.1 \pm 4.9^{\mathrm{a}} \\
90.0 \pm 7.4\end{array}$ & $\begin{array}{l}91.8 \pm 6.1^{\mathrm{a}} \\
90.2 \pm 7.0^{\mathrm{a}}\end{array}$ & $\begin{array}{l}93.2 \pm 5.1^{\mathrm{b}} \\
91.0 \pm 7.0^{\mathrm{a}}\end{array}$ & $\begin{array}{l}95.3 \pm 4.2^{\mathrm{b}} \\
91.9 \pm 7.7^{\mathrm{b}}\end{array}$ \\
\hline
\end{tabular}

${ }^{\mathrm{a}} \mathrm{P}<0.05,{ }^{\mathrm{b}} \mathrm{P}<0.01$ (comparison between baseline and $4,8,12$ and 16 weeks).
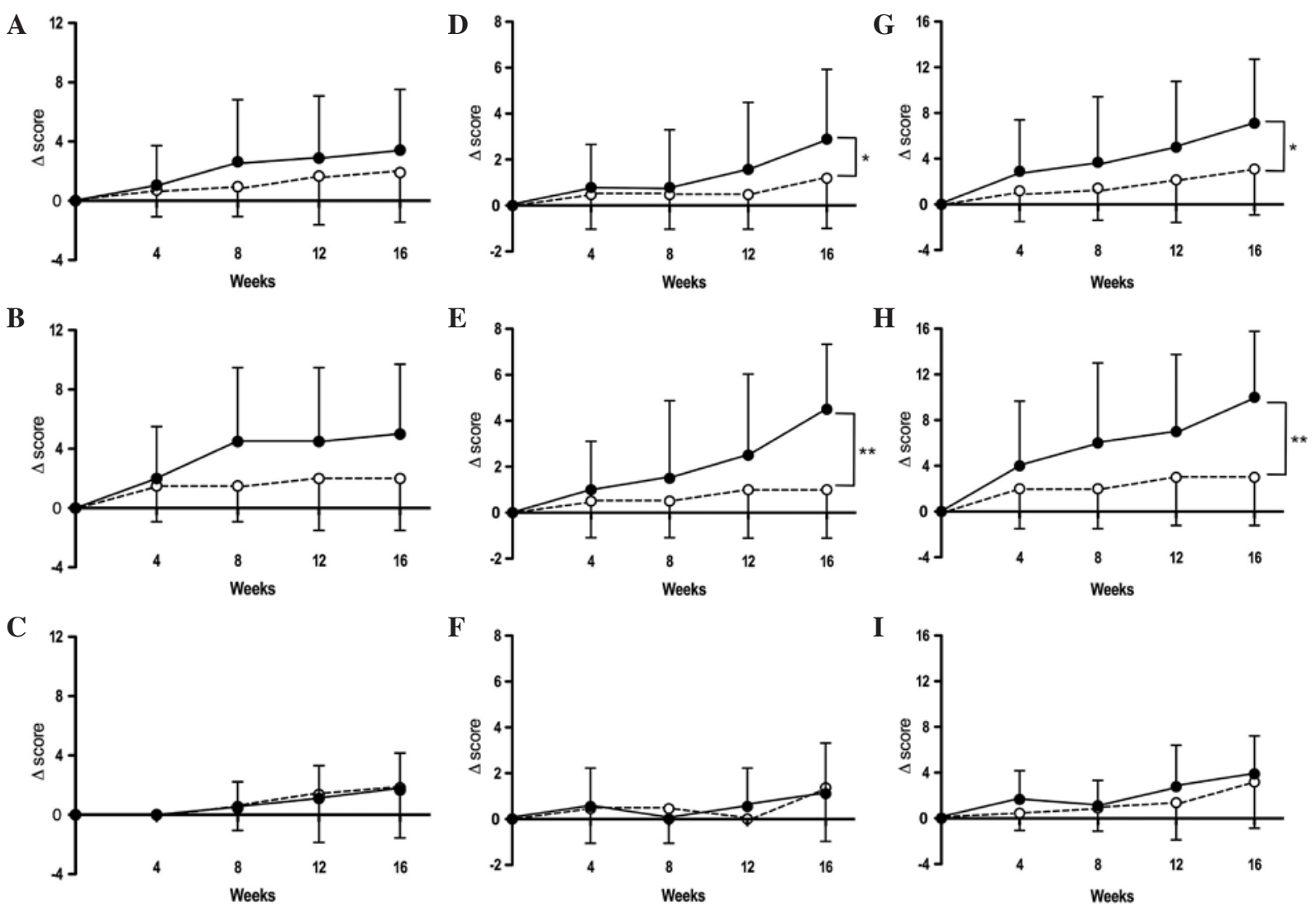

Figure 1. Changes in the three subscale scores of the JOA response criteria from baseline during the intervention for all subjects (A, D and G), ET-receivers $(\mathrm{B}, \mathrm{E}$ and $\mathrm{H})$ and ET-unreceivers $(\mathrm{C}, \mathrm{F}$ and $\mathrm{I})$ of the active diet group $(\bullet)$ and the placebo group (O). The three subscale scores are 'pain/walking function' (A-C), 'pain/step-up and -down function' (D-F) and 'aggregate total symptoms' (G-I). 'P<0.05; ${ }^{* *} \mathrm{P}<0.01$.

scores in the active diet group were significantly increased compared to those in the placebo group at week $16(\mathrm{P}<0.05)$.

In order to determine whether concurrent ET influences the symptomatic response to the active diet, ET-receivers and ET-unreceivers in both groups (active diet and placebo) were separately analyzed. As shown in Table III, among the
ET-receivers of the active diet group, 'pain/walking function' and 'aggregate total symptoms' scores significantly increased at weeks 8, 12 and $16(\mathrm{P}<0.05)$, and the 'pain/step-up and -down function' score significantly increased at week 16 $(\mathrm{P}<0.05)$ compared to the baseline. By contrast, in the ET-unreceivers of the active diet group, these subscale scores 
Table III. Changes in the three subscale scores of JOA response criteria during intervention for ET-receivers and ET-unreceivers in the active diet and the placebo groups.

\begin{tabular}{|c|c|c|c|c|c|c|}
\hline \multirow[t]{2}{*}{ Subscales } & \multirow[t]{2}{*}{ Group, subjects } & \multicolumn{5}{|c|}{ Scores $($ mean $\pm \mathrm{SD})$} \\
\hline & & Baseline & 4 weeks & 8 weeks & 12 weeks & 16 weeks \\
\hline \multirow[t]{4}{*}{ I. Pain/walking function } & Active diet, ET-receivers $(n=10)$ & $24.5 \pm 5.0$ & $26.5 \pm 4.1$ & $29.0 \pm 3.2^{\mathrm{a}}$ & $29.0 \pm 3.2^{\mathrm{a}}$ & $29.5 \pm 1.6^{\mathrm{a}}$ \\
\hline & Placebo, ET-receivers $(\mathrm{n}=10)$ & $24.5 \pm 3.7$ & $26.0 \pm 3.9$ & $26.0 \pm 3.9$ & $26.5 \pm 4.1$ & $26.5 \pm 4.1$ \\
\hline & Active diet, ET-unreceivers $(n=9)$ & $28.3 \pm 2.5$ & $28.3 \pm 2.5$ & $28.9 \pm 2.2$ & $29.4 \pm 1.7$ & $30.0 \pm 0.0$ \\
\hline & Placebo, ET-unreceivers $(\mathrm{n}=11)$ & $27.3 \pm 4.7$ & $27.3 \pm 4.7$ & $27.7 \pm 3.4$ & $28.6 \pm 2.3$ & $29.1 \pm 2.0$ \\
\hline \multirow{4}{*}{$\begin{array}{l}\text { II. Pain/step-up and } \\
\text {-down function }\end{array}$} & Active diet, ET-receivers $(\mathrm{n}=10)$ & $19.5 \pm 1.6$ & $20.5 \pm 1.6$ & $21.0 \pm 2.1$ & $22.0 \pm 2.6$ & $24.0 \pm 2.1^{\mathrm{b}}$ \\
\hline & Placebo, ET-receivers $(\mathrm{n}=10)$ & $19.0 \pm 2.1$ & $19.5 \pm 2.8$ & $19.5 \pm 2.8$ & $20.0 \pm 3.3$ & $20.0 \pm 3.3$ \\
\hline & Active diet, ET-unreceivers $(n=9)$ & $19.4 \pm 1.7$ & $20.0 \pm 0.0$ & $19.4 \pm 1.7$ & $20.0 \pm 0.0$ & $20.6 \pm 1.7$ \\
\hline & Placebo, ET-unreceivers $(\mathrm{n}=11)$ & $20.0 \pm 0.0$ & $20.5 \pm 1.5$ & $20.5 \pm 1.5$ & $20.0 \pm 0.0$ & $21.4 \pm 2.3$ \\
\hline \multirow[t]{4}{*}{ V. Aggregate total symptoms } & Active diet, ET-receivers $(\mathrm{n}=10)$ & $87.0 \pm 6.7$ & $91.0 \pm 4.6$ & $93.0 \pm 5.4^{\mathrm{a}}$ & $94.0 \pm 5.7^{\mathrm{a}}$ & $97.0 \pm 3.5^{\mathrm{b}}$ \\
\hline & Placebo, ET-receivers $(\mathrm{n}=10)$ & $86.0 \pm 7.4$ & $88.0 \pm 8.6$ & $88.0 \pm 8.6$ & $89.0 \pm 9.4$ & $89.0 \pm 9.4$ \\
\hline & Active diet, ET-unreceivers $(n=9)$ & $89.4 \pm 6.8$ & $91.1 \pm 5.5$ & $90.6 \pm 6.8$ & $92.2 \pm 4.4$ & $93.3 \pm 4.3^{\mathrm{a}}$ \\
\hline & Placebo, ET-unreceivers $(\mathrm{n}=11)$ & $91.4 \pm 6.0$ & $91.8 \pm 6.0$ & $92.3 \pm 4.7$ & $92.7 \pm 3.4$ & $94.5 \pm 4.7^{\mathrm{a}}$ \\
\hline
\end{tabular}

${ }^{\mathrm{a}} \mathrm{P}<0.05,{ }^{\mathrm{b}} \mathrm{P}<0.01$ (comparison between baseline and $4,8,12$ and 16 weeks).

Table IV. Changes in the three subscale scores of VAS during intervention for all subjects, ET-receivers and ET-unreceivers in the active diet and the placebo groups.

\begin{tabular}{|c|c|c|c|c|c|c|}
\hline \multirow[t]{2}{*}{ Subscales } & \multirow[t]{2}{*}{ Group, subjects } & \multicolumn{5}{|c|}{$\operatorname{VAS}(\mathrm{mm})($ mean $\pm \mathrm{SD})$} \\
\hline & & Baseline & 4 weeks & 8 weeks & 12 weeks & 16 weeks \\
\hline \multirow[t]{6}{*}{ I. Pain at rest } & Active diet, all subjects ( $\mathrm{n}=9$ ) & $55.4 \pm 8.6$ & $35.6 \pm 14.6^{\mathrm{b}}$ & $23.6 \pm 11.1^{\mathrm{b}}$ & $21.1 \pm 11.2^{\mathrm{b}}$ & $12.6 \pm 6.3^{b}$ \\
\hline & Placebo, all subjects $(n=12)$ & $54.7 \pm 8.5$ & $37.9 \pm 12.0^{\mathrm{b}}$ & $29.7 \pm 18.4^{b}$ & $25.2 \pm 18.4^{\mathrm{b}}$ & $22.2 \pm 21.5^{b}$ \\
\hline & Active diet, ET-receivers $(n=5)$ & $50.2 \pm 5.1$ & $38.1 \pm 18.6$ & $20.7 \pm 13.1^{b}$ & $22.2 \pm 13.4^{\mathrm{a}}$ & $14.4 \pm 7.7^{\mathrm{b}}$ \\
\hline & Placebo, ET-receivers $(n=5)$ & $52.9 \pm 7.8$ & $35.0 \pm 13.5^{\mathrm{a}}$ & $30.3 \pm 9.7^{\mathrm{b}}$ & $27.6 \pm 11.0^{\mathrm{a}}$ & $20.9 \pm 11.9^{b}$ \\
\hline & Active diet, ET-unreceivers $(n=4)$ & $61.9 \pm 7.8$ & $32.4 \pm 9.2^{\mathrm{b}}$ & $27.2 \pm 8.2^{\mathrm{b}}$ & $19.7 \pm 9.6^{\mathrm{b}}$ & $10.4 \pm 4.0^{\mathrm{b}}$ \\
\hline & Placebo, ET-unreceivers $(\mathrm{n}=7)$ & $56.0 \pm 9.4$ & $40.0 \pm 11.4^{\mathrm{a}}$ & $29.2 \pm 23.6^{\mathrm{a}}$ & $23.5 \pm 23.0^{b}$ & $23.2 \pm 27.3^{\mathrm{a}}$ \\
\hline \multirow[t]{6}{*}{ II. Pain on moving } & Active diet, all subjects $(n=19)$ & $64.3 \pm 13.1$ & $42.9 \pm 14.2^{b}$ & $35.6 \pm 13.8^{b}$ & $31.2 \pm 15.5^{b}$ & $24.2 \pm 13.2^{\mathrm{b}}$ \\
\hline & Placebo, all subjects $(n=19)$ & $61.8 \pm 12.4$ & $45.2 \pm 15.9^{\mathrm{b}}$ & $39.7 \pm 18.0^{\mathrm{b}}$ & $36.7 \pm 15.7^{\mathrm{b}}$ & $25.3 \pm 16.2^{\mathrm{b}}$ \\
\hline & Active diet, ET-receivers $(\mathrm{n}=10)$ & $62.7 \pm 11.2$ & $43.6 \pm 12.0^{\mathrm{b}}$ & $31.6 \pm 13.7^{\mathrm{b}}$ & $28.8 \pm 15.9^{b}$ & $25.6 \pm 13.1^{\mathrm{b}}$ \\
\hline & Placebo, ET-receivers $(\mathrm{n}=10)$ & $63.8 \pm 12.6$ & $43.2 \pm 19.2^{\mathrm{b}}$ & $42.9 \pm 16.0^{\mathrm{b}}$ & $37.3 \pm 11.6^{\mathrm{b}}$ & $24.9 \pm 9.4^{\mathrm{b}}$ \\
\hline & Active diet, ET-unreceivers $(n=9)$ & $66.1 \pm 15.3$ & $42.3 \pm 17.0^{\mathrm{b}}$ & $40.1 \pm 13.2^{b}$ & $34.0 \pm 15.4^{\mathrm{b}}$ & $22.6 \pm 13.9^{b}$ \\
\hline & Placebo, ET-unreceivers $(\mathrm{n}=9)$ & $59.7 \pm 12.7$ & $47.4 \pm 12.1^{\mathrm{a}}$ & $36.1 \pm 20.5^{\mathrm{a}}$ & $36.1 \pm 20.1^{\mathrm{a}}$ & $25.8 \pm 22.1^{\mathrm{b}}$ \\
\hline \multirow[t]{6}{*}{ III. Pain on pressing } & Active diet, all subjects $(n=13)$ & $66.0 \pm 14.5$ & $46.4 \pm 20.5^{b}$ & $39.6 \pm 14.8^{b}$ & $24.1 \pm 17.7^{\mathrm{b}}$ & $20.3 \pm 14.4^{\mathrm{b}}$ \\
\hline & Placebo, all subjects $(n=15)$ & $61.0 \pm 13.2$ & $50.1 \pm 13.7^{b}$ & $38.6 \pm 16.5^{b}$ & $32.1 \pm 15.1^{\mathrm{b}}$ & $26.9 \pm 18.4^{\mathrm{b}}$ \\
\hline & Active diet, ET-receivers $(\mathrm{n}=7)$ & $65.2 \pm 18.8$ & $48.8 \pm 19.0^{\mathrm{a}}$ & $38.5 \pm 18.3^{b}$ & $21.8 \pm 18.8^{\mathrm{b}}$ & $21.6 \pm 14.4^{\mathrm{b}}$ \\
\hline & Placebo, ET-receivers $(\mathrm{n}=7)$ & $55.5 \pm 10.4$ & $47.9 \pm 13.3^{\mathrm{a}}$ & $40.0 \pm 8.2^{\mathrm{a}}$ & $29.8 \pm 12.5^{\mathrm{b}}$ & $24.9 \pm 12.1^{\mathrm{b}}$ \\
\hline & Active diet, ET-unreceivers $(n=6)$ & $67.0 \pm 8.6$ & $43.8 \pm 23.7^{\mathrm{a}}$ & $40.8 \pm 10.9^{b}$ & $26.8 \pm 17.8^{b}$ & $18.7 \pm 15.6^{\mathrm{b}}$ \\
\hline & Placebo, ET-unreceivers $(\mathrm{n}=8)$ & $65.7 \pm 14.2$ & $52.0 \pm 14.7$ & $37.4 \pm 22.0^{\mathrm{a}}$ & $34.1 \pm 17.7^{\mathrm{b}}$ & $28.6 \pm 23.3^{\mathrm{b}}$ \\
\hline
\end{tabular}

${ }^{\mathrm{a}} \mathrm{P}<0.05,{ }^{\mathrm{b}} \mathrm{P}<0.01$ (comparison between baseline and $4,8,12$ and 16 weeks).

did not essentially increase during the intervention, although the 'aggregate total symptoms' scores significantly increased at week $16(\mathrm{P}<0.05)$. In the placebo group, only the 'aggregate total symptoms' subscale score slightly increased at week 16 in ET-unreceivers $(\mathrm{P}<0.05)$. Consistent with these observations, the changes in subscale scores from baseline were significantly or 
A

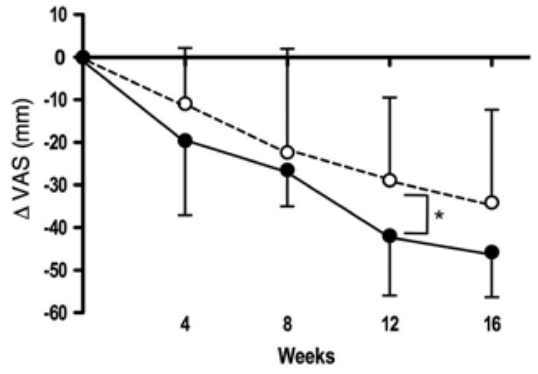

B

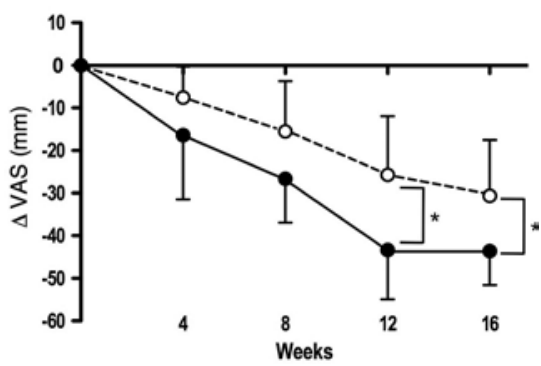

C

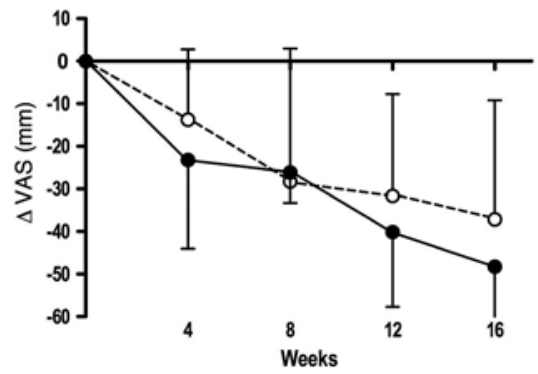

Figure 2. Changes in the VAS subscale score of 'pain on pressing' from baseline during intervention for all subjects (A), ET-receivers (B) and ET-unreceivers $(C)$ of the active diet group $(\bullet)$ and the placebo group (O). ${ }^{*} \mathrm{P}<0.05$.

almost significantly increased in the ET-receivers of the active diet group compared to those of the placebo group for subscale scores of 'pain/step-up and -down function' ( $\mathrm{P}<0.01)$, 'aggregate total symptoms' $(\mathrm{P}<0.01)$ and 'pain/walking function' $(\mathrm{P}=0.09)$ at week 16 (Fig. 1). However, there was no significant difference in the changes of these three subscale scores from baseline in ET-unreceivers of the two groups (active diet and placebo) throughout the intervention period (Fig. 1).

Assessment based on the pain scores of VAS. The pain-relieving effect was assessed using the three subscales of VAS. The number of subjects enrolled for the assessment were 9 (5 ET-receivers and 4 ET-unreceivers) and 12 (5 ET-receivers and 7 ET-unreceivers) for 'pain at rest', 19 (10 ET-receivers and 9 ET-unreceivers) each for 'pain on moving' and 13 (7 ET-receivers and 6 ET-unreceivers) and 15 (7 ET-receivers and 8 ET-unreceivers) for 'pain on pressing' in the active diet and the placebo groups, respectively.

As shown in Table IV, the three subscale scores of VAS were reduced from baseline in both the active diet and the placebo groups during the intervention (4-16 weeks) $(\mathrm{P}<0.05$, indicative of pain relief). Similarly, the three subscale scores of VAS were reduced in both the ET-receivers and ET-unreceivers of the two groups $(\mathrm{P}<0.05)$. Notably, the 'pain on pressing' subscale scores were significantly decreased from baseline in ET-receivers as well as in all subjects of the active diet group compared to those of the placebo group at weeks 12 and 16 (Fig. 2, P<0.05).

Assessment based on CII metabolism. To evaluate the effect on CII metabolism, urine and serum samples were collected at baseline and three time points (weeks 8,12 and 16) from all subjects, except urine samples from 1 ET-unreceiver in the active diet group.

Table V shows the changes in the levels of uCTX-II, sC2C and sCPII in the active diet and the placebo groups during the 16-week intervention. In the entire subject population, the uCTX-II level slightly decreased during the intervention in both groups (indicating the suppression of CII degradation), although the change from baseline was significant only in the placebo group at week $16(\mathrm{P}<0.05)$.

By contrast, the $\mathrm{sC} 2 \mathrm{C}$ level was significantly increased in the active diet group compared to the placebo group at weeks 8,12 and $16(\mathrm{P}<0.05)$. In the subgroup analyses, sC2C levels were significantly increased in both ET-receivers and ET-unreceivers of the active diet group at week $12(\mathrm{P}<0.01$ each) and in ET-receivers of the placebo group at weeks 8 and 12 ( $\mathrm{P}<0.05$ each). Furthermore, the changes in $\mathrm{sC} 2 \mathrm{C}$ levels from baseline were significantly increased in all subjects and ET-unreceivers of the active diet group compared to those of the placebo group $(\mathrm{P}<0.01$ each) (data not shown).

Of note, the sCPII levels were significantly increased from baseline in all subjects (week 12, $\mathrm{P}<0.01$ ), ET-receivers (week 12, $\mathrm{P}<0.05$ ) and ET-unreceivers (weeks 8 and 12, $\mathrm{P}<0.05$ ) of the active diet group (indicating the enhancement of CII synthesis), although CPII levels remained almost constant over the 16-week intervention period in the placebo group.

To further determine whether ingestion of the active diet affects the synthesis of CII relative to its degradation, we evaluated the ratio of the CII degradation marker (uCTX-II or sC2C) to the CII synthesis marker (sCPII). As shown in Table VI, compared to baseline, the uCTX-II/sCPII ratio was reduced by $20-35 \%$ at weeks 8,12 and $16(\mathrm{P}<0.05)$ in all subjects of the active diet group (indicating the relative enhancement of CII synthesis). The ratio was also reduced in ET-receivers at week $12(-27 \% ; \mathrm{P}<0.05)$ and ET-unreceivers at week $12(-41 \% ; \mathrm{P}<0.05)$ and at week $16(-32 \%$; $\mathrm{P}<0.05)$ in the active diet group. Furthermore, the $\mathrm{sC} 2 \mathrm{C} / \mathrm{sCPII}$ ratio was significantly reduced in all subjects at week $12(-12 \% ; \mathrm{P}<0.05)$ and ET-unreceivers at week $8(-18 \% ; \mathrm{P}<0.05)$ and week 12 $(-15 \% ; \mathrm{P}<0.05)$ in the active diet group. By contrast, none of the subjects in the placebo group showed a significant change in either parameter during the intervention.

Fig. 3 illustrates the decrease from baseline in the uCTX-II/CPII and C2C/CPII ratios in the active diet and the placebo groups during the intervention period. Both parameters were substantially decreased in all subjects, particularly in ET-unreceivers of the active diet group compared to those in the placebo group; the changes were significantly larger in ET-unreceivers of the active diet group than in those of the placebo group for the uCTX-II/CPII ratio at week $12(\mathrm{P}<0.05)$ and the $\mathrm{C} 2 \mathrm{C} / \mathrm{CPII}$ ratio at week $8(\mathrm{P}<0.05)$.

Safety and tolerability. Nine subjects (43\%) of the active diet group $(n=21)$ and 12 subjects $(55 \%)$ of the placebo group $(n=22)$ were reported to have experienced one or more adverse 
Table V. Changes in the levels of CII metabolism biomarkers urinary CTX-II, serum C2C and serum CPII during intervention for all subjects, ET-receivers and ET-unreceivers in the active diet and the placebo groups.

\begin{tabular}{|c|c|c|c|c|c|}
\hline \multirow[t]{2}{*}{ Biomarkers } & \multirow[t]{2}{*}{ Group, subjects } & \multicolumn{4}{|c|}{ Concentration (mean $\pm \mathrm{SD})$} \\
\hline & & Baseline & 8 weeks & 12 weeks & 16 weeks \\
\hline \multirow[t]{6}{*}{ Urinary CTX-II (ng/mmol Cr) } & Active diet, all subjects $(\mathrm{n}=18)^{\mathrm{a}}$ & $397 \pm 193$ & $360 \pm 163$ & $361 \pm 172$ & $363 \pm 172$ \\
\hline & Placebo, all subjects $(\mathrm{n}=21)$ & $350 \pm 135$ & $338 \pm 153$ & $317 \pm 118$ & $292 \pm 105^{b}$ \\
\hline & Active diet, ET-receivers $(\mathrm{n}=10)$ & $372 \pm 211$ & $349 \pm 186$ & $354 \pm 207$ & $355 \pm 203$ \\
\hline & Placebo, ET-receivers $(\mathrm{n}=10)$ & $352 \pm 123$ & $349 \pm 172$ & $330 \pm 136$ & $296 \pm 99$ \\
\hline & Active diet, ET-unreceivers $(\mathrm{n}=8)^{\mathrm{a}}$ & $428 \pm 178$ & $374 \pm 140$ & $371 \pm 131$ & $373 \pm 135$ \\
\hline & Placebo, ET-unreceivers $(\mathrm{n}=11)$ & $348 \pm 151$ & $328 \pm 141$ & $304 \pm 104$ & $289 \pm 116$ \\
\hline \multirow[t]{6}{*}{ Serum C2C (ng/ml) } & Active diet, all subjects $(\mathrm{n}=19)$ & $224 \pm 39$ & $237 \pm 25^{b}$ & $271 \pm 39^{c}$ & $249 \pm 47^{b}$ \\
\hline & Placebo, all subjects $(\mathrm{n}=21)$ & $222 \pm 22$ & $236 \pm 33$ & $232 \pm 31$ & $231 \pm 26$ \\
\hline & Active diet, ET-receivers $(n=10)$ & $217 \pm 42$ & $236 \pm 23$ & $254 \pm 27^{c}$ & $234 \pm 20$ \\
\hline & Placebo, ET-receivers $(\mathrm{n}=10)$ & $220 \pm 26$ & $246 \pm 39^{b}$ & $239 \pm 29^{b}$ & $236 \pm 18$ \\
\hline & Active diet, ET-unreceivers (n=9) & $231 \pm 36$ & $237 \pm 27$ & $290 \pm 44^{c}$ & $264 \pm 63$ \\
\hline & Placebo, ET-unreceivers $(\mathrm{n}=11)$ & $224 \pm 19$ & $226 \pm 24$ & $227 \pm 34$ & $226 \pm 32$ \\
\hline \multirow[t]{6}{*}{ Serum CPII (ng/ml) } & Active diet, all subjects $(n=19)$ & $1,168 \pm 419$ & $1,277 \pm 314$ & $1,559 \pm 367^{\mathrm{c}}$ & $1,382 \pm 368$ \\
\hline & Placebo, all subjects $(\mathrm{n}=21)$ & $1,614 \pm 629$ & $1,699 \pm 423$ & $1,788 \pm 650$ & $1,663 \pm 612$ \\
\hline & Active diet, ET-receivers $(\mathrm{n}=10)$ & $1,312 \pm 519$ & $1,274 \pm 362$ & $1,585 \pm 301^{\mathrm{b}}$ & $1,388 \pm 271$ \\
\hline & Placebo, ET-receivers $(\mathrm{n}=10)$ & $1,532 \pm 833$ & $1,623 \pm 492$ & $1,772 \pm 740$ & $1,564 \pm 525$ \\
\hline & Active diet, ET-unreceivers (n=9) & $1,007 \pm 189$ & $1,281 \pm 274^{b}$ & $1,531 \pm 446^{c}$ & $1,376 \pm 470^{b}$ \\
\hline & Placebo, ET-unreceivers $(\mathrm{n}=11)$ & $1,690 \pm 392$ & $1,768 \pm 359$ & $1,802 \pm 594$ & $1,752 \pm 695$ \\
\hline
\end{tabular}

${ }^{\mathrm{a} U r i n e}$ samples were not collected from 1 ET-unreceiver in the active diet group. ${ }^{\mathrm{b}} \mathrm{P}<0.05,{ }^{\mathrm{c}} \mathrm{P}<0.01$ (comparison between baseline and 8,12 and 16 weeks).

Table VI. Changes in the ratios of CII degradation marker to synthesis marker, uCTX-II/sCPII and sC2C/sCPII, during intervention for all subjects, ET-receivers and ET-unreceivers in the active diet and the placebo groups.

\begin{tabular}{|c|c|c|c|c|c|}
\hline \multirow[t]{2}{*}{ Ratios } & \multirow[t]{2}{*}{ Group, subjects } & \multicolumn{4}{|c|}{ Concentration ratio $(\text { mean } \pm \mathrm{SD})^{\mathrm{a}}$} \\
\hline & & Baseline & 8 weeks & 12 weeks & 16 weeks \\
\hline \multirow[t]{6}{*}{ uCTX-II/sCPII } & Active diet, all subjects $(\mathrm{n}=17)$ & $0.355 \pm 0.178$ & $0.284 \pm 0.124^{\mathrm{b}}$ & $0.232 \pm 0.100^{\mathrm{c}}$ & $0.270 \pm 0.123^{\mathrm{b}}$ \\
\hline & Placebo, all subjects $(\mathrm{n}=21)$ & $0.246 \pm 0.126$ & $0.214 \pm 0.120$ & $0.206 \pm 0.126$ & $0.204 \pm 0.115$ \\
\hline & Active diet, ET-receivers $(n=10)$ & $0.295 \pm 0.149$ & $0.270 \pm 0.104$ & $0.215 \pm 0.102^{\mathrm{b}}$ & $0.255 \pm 0.132$ \\
\hline & Placebo, ET-receivers $(n=10)$ & $0.281 \pm 0.149$ & $0.243 \pm 0.157$ & $0.229 \pm 0.164$ & $0.217 \pm 0.122$ \\
\hline & Active diet, ET-unreceivers $(\mathrm{n}=8)$ & $0.429 \pm 0.193$ & $0.301 \pm 0.150$ & $0.253 \pm 0.099^{\mathrm{b}}$ & $0.290 \pm 0.115^{\mathrm{b}}$ \\
\hline & Placebo, ET-unreceivers $(\mathrm{n}=11)$ & $0.215 \pm 0.098$ & $0.187 \pm 0.070$ & $0.185 \pm 0.082$ & $0.193 \pm 0.113$ \\
\hline \multirow[t]{6}{*}{$\mathrm{sC} 2 / \mathrm{sCPII}$} & Active diet, all subjects $(n=19)$ & $0.204 \pm 0.047$ & $0.192 \pm 0.034$ & $0.180 \pm 0.036^{\mathrm{b}}$ & $0.187 \pm 0.040$ \\
\hline & Placebo, all subjects $(\mathrm{n}=21)$ & $0.151 \pm 0.039$ & $0.147 \pm 0.041$ & $0.142 \pm 0.041$ & $0.154 \pm 0.050$ \\
\hline & Active diet, ET-receivers $(\mathrm{n}=10)$ & $0.179 \pm 0.046$ & $0.194 \pm 0.036$ & $0.164 \pm 0.026$ & $0.173 \pm 0.031$ \\
\hline & Placebo, ET-receivers $(n=10)$ & $0.165 \pm 0.048$ & $0.162 \pm 0.046$ & $0.150 \pm 0.045$ & $0.163 \pm 0.044$ \\
\hline & Active diet, ET-unreceivers $(n=9)$ & $0.232 \pm 0.030$ & $0.190 \pm 0.035^{\mathrm{b}}$ & $0.198 \pm 0.037^{\mathrm{b}}$ & $0.203 \pm 0.044$ \\
\hline & Placebo, ET-unreceivers ( $\mathrm{n}=11)$ & $0.137 \pm 0.026$ & $0.133 \pm 0.033$ & $0.136 \pm 0.038$ & $0.146 \pm 0.055$ \\
\hline
\end{tabular}

${ }^{\mathrm{a} C a l c u l a t e d}$ from data shown in Table $\mathrm{V}$. ${ }^{\mathrm{b}} \mathrm{P}<0.05,{ }^{\mathrm{c}} \mathrm{P}<0.01$ (comparison between baseline and 8,12 and 16 weeks).

events during the intervention period. The total number of adverse events reported were 45 in the active diet group and 32 in the placebo group, and there was no significant differ- ence in the frequency between the two groups. Major adverse events and their frequencies in the active diet and the placebo groups were: cold symptoms (12 vs. 3); pain (6 vs. 6); myalgia 
A

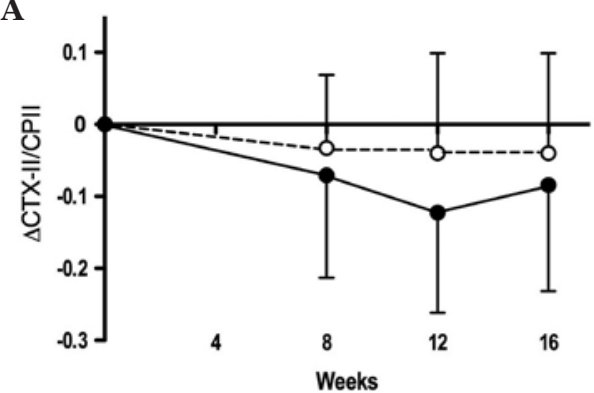

B

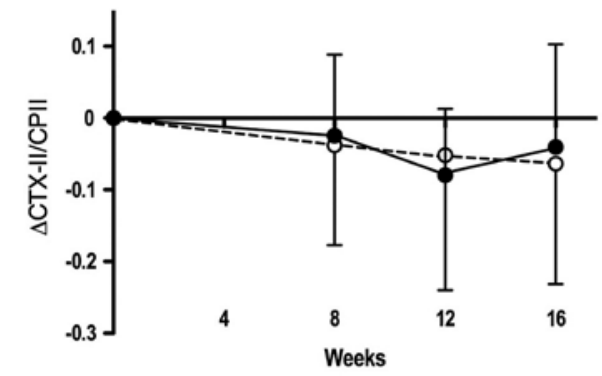

C

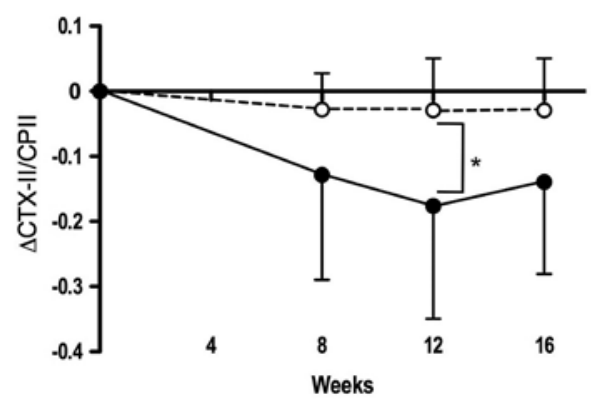

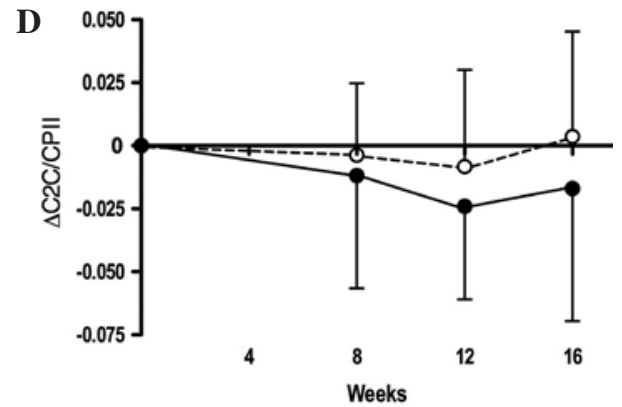

$\mathbf{E}$

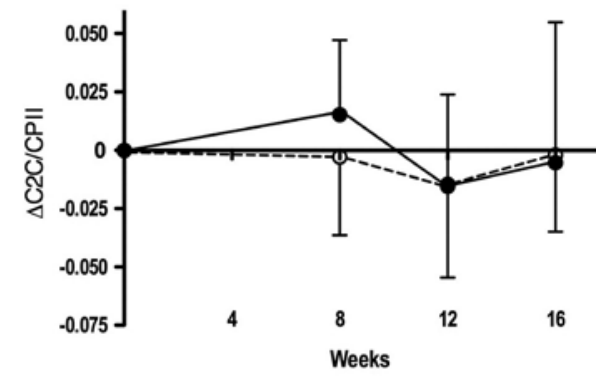

F

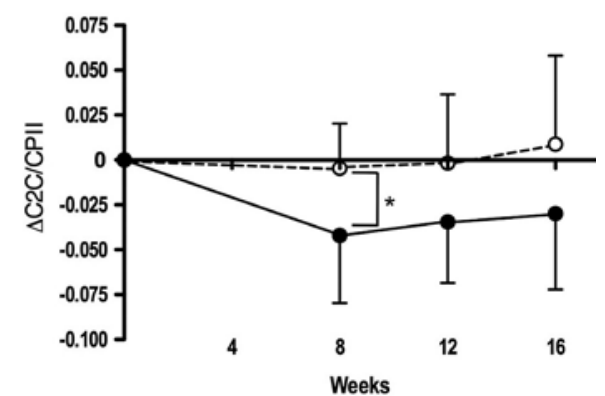

Figure 3. Changes in the uCTX-II/sCPII (A-C) and sC2C/sCPII (D-F) ratios from baseline during intervention for all subjects (A and D), ET-receivers (B and E) and ET-unreceivers $(\mathrm{C}$ and $\mathrm{F})$ of the active diet $(\bullet)$ and placebo $(\mathrm{O})$ groups. ${ }^{*} \mathrm{P}<0.05$.

(6 vs. 5); gastric discomfort (6 vs. 3); diarrhea (3 vs. 4); and cramp (2 vs. 2). None of these adverse events were severe and all were considered to be unrelated to the study diet.

Furthermore, none of the physical measurement parameters (body weight and body mass index), physiological examinations (systolic/diastolic blood pressures and pulse rate) and laboratory tests (hematology and blood chemistry) were significantly changed from baseline in either of the groups.

\section{Discussion}

In this study, we performed a randomized double-blind placebo-controlled clinical trial utilizing a supplementary diet containing HA-rich CCE to subjects with mild knee OA (mainly 1-2 of K/L grades). First, we assessed the potential of the oral administration of HA in the management of knee OA, since little information is available on its effect, although the intra-articular administration of HA has almost been established in knee OA. Second, in addition to the symptommodifying (improving) effect of the oral administration of HA, we examined its potential for a structure-modifying (chondroprotective) effect. Third, we investigated the contribution of ET to the symptomatic and/or chondroprotective effects of the oral administration of HA. For this purpose, subgroup analyses were performed between ET-receivers and ET-unreceivers in the two different groups (active diet and placebo).

The present study revealed that the CCE-containing diet, used as an active diet, has the potential to relieve pain and disability in subjects with knee OA based on an assessment using the JOA response criteria. In the entire subject population, the subscale scores of 'pain/walking function', 'pain/ step-up and -down function' and 'aggregate total symptoms' were increased (improved) to a greater extent from baseline in the active diet group compared to the placebo group during the intervention (Table II). Moreover, the 'pain/step-up and -down function' and 'aggregate total symptoms' subscale scores were significantly increased from baseline in the active diet group at week 16 compared to the placebo group (Fig. 1). By contrast, neither the active diet nor the placebo affected the remaining two subscale scores, 'joint flexion/stiffness' and 'swelling' (Table II). The former likely suggests that the active diet confers no effect on 'joint flexion/stiffness' suffered by the subjects enrolled, and the latter can be explained by the fact that none of the subjects exhibited swelling in the affected knee.

VAS assessment indicated that pain scores for the three subscales were significantly reduced (improved) from baseline 
during the intervention in both the active diet and the placebo groups (Table IV). Such a placebo effect has been reported in clinical studies on OA conducted for relatively short periods ( $\sim 8$ weeks) (23). However, the 'pain on pressing' subscale was significantly decreased from baseline in the active diet group compared to the placebo group (Fig. 2). These results were essentially concordant with those obtained by Hatayama et al (16), who previously indicated that the 2 -week intake of the same CCE-containing diet $(1,800 \mathrm{mg} /$ day $)$ was effective in relieving knee pain in subjects with OA.

Consistent with our observation, oral administration of HA [a product of purified HA (Hyabest ${ }^{\circledR}(\mathrm{J}), 240 \mathrm{mg} /$ day) (23) and a natural extract of chicken combs with a high HA content (Hyal-Joint $^{\circledR}, \sim 50 \mathrm{mg} /$ day) (24)] has been reported to relieve pain and other discomforts in knee OA, 4-8 weeks after the intervention. Together, these observations indicate that oral supplementation of an HA-containing diet has potential as a symptom-modifying agent in knee OA.

It was important to examine whether the concurrent ET affects the symptom-improving effect of the active diet in patients with knee OA. In this study, the subgroup analyses between tET-receivers and ET-unreceivers indicated that three of five subscale scores of the JOA response criteria, as well as one of the three subscale scores of VAS, were significantly improved in the ET-receivers of the active diet group at one or more time points during the intervention. In accordance with this, several randomized placebo-controlled trials have suggested that ET reduces pain and improves physical function in patients with OA (25). In fact, Roos and Dahlberg found that moderate exercise improves not only joint symptoms and function, but also the knee cartilage glucosaminoglycan content in patients with knee OA (26). Thus, oral supplementation of HA is expected to be more effective in relieving disability and pain in knee OA when combined with ET.

Accumulating evidence indicates that biomarkers for cartilage metabolism, particularly CII metabolism, can be used in OA not only for screening patients with a risk of progressive joint destruction, but also for monitoring structure-modifying agents or therapies (19). Using CII degradation biomarkers such as CTX-II, C1, 2C and C2C, the actions of chondroprotective agents, i.e., glucosamine $(27,28)$ and chondroitin sulfate (29), have been evaluated. More recently, CII synthesis biomarkers, such as CPII (PIICP), have been used alone or in combination with CII degradation biomarkers (e.g., CTX-II and $\mathrm{C} 2 \mathrm{C}$ ) for monitoring the disease state and progression of knee OA. In the present study, to evaluate the effect of the active diet on cartilage CII metabolism, we utilized two CII degradation biomarkers (CTX-II and C2C) and one CII synthesis biomarker (CPII).

At first we assumed that, if the active diet exhibited a chondroprotective action, the levels of both uCTX-II and sC2C would be reduced, whereas the level of sCPII would be increased. In accordance with our assumption, the active diet caused a significant increase in the level of sCPII (Table V). However, the uCTX-II levels were not essentially decreased in the active diet group. Furthermore, the $\mathrm{sC} 2 \mathrm{C}$ levels were significantly increased in the active diet group. Although the mechanism for the discrepancy between changes in the levels of uCTX-II and $\mathrm{sC} 2 \mathrm{C}$ during the intervention remains to be elucidated, it could be explained by the fact that $\mathrm{C} 2 \mathrm{C}$ and CTX-II originate from different domains of CII (the telopeptide and triple helix regions, respectively), and they are believed to reflect the distinct breakdown events of CII by different enzymatic pathways (30). We also evaluated the action of the active diet on CII metabolism using the ratio of the CII degradation biomarker to the CII synthesis biomarker. Both the uCTX-II/CPII and C2C/CPII ratios were decreased during the intervention in all subjects, particularly in the ET-unreceivers of the active diet group (Table VI and Fig. 3). Thus, the combination of the two biomarkers (CII degradation and synthesis biomarkers) seems to be more effective than measuring a single biomarker in monitoring the action of chondroprotective agents on CII metabolism in OA. In this context, Cahue et al (22) demonstrated that the ratio of CII breakdown to synthesis can be used to predict the progression of knee OA. Together, these observations likely indicate that intervention with the active diet containing HA may have a chondroprotective action on knee OA by relatively enhancing CII synthesis, particularly in ET-unreceivers. However, this possibility should be cautiously confirmed in future, since in the present study the baseline levels of sCPII were significantly lower in the active diet group than in the placebo group.

In general, oral administration of HA may have an advantage over intra-articular HA injection, as it can circumvent potential complications at the injection site and the discomfort associated with repeated injections (14). The present study provided evidence for the safety and symptom-relieving effect of the active diet as a promising candidate for oral HA supplementation. Moreover, this study indicated that the active diet is likely to improve the balance of CII degradation/ synthesis, thereby conferring potential chondroprotection against OA. Based on these results, it is suggested that the CCE-containing diet could be a non-surgical management for knee OA via the actions of not only relieving pain and functional disability, but also by protecting articular cartilage. However, to further elucidate the beneficial effect of the CCE-containing diet on knee OA, the actions of propolis extracts and other constituents contained in the active diet should be determined.

\section{Acknowledgements}

We wish to thank Kaori Yoshimura and Reiko Kojima (Total Technological Consultant Co., Ltd., Tokyo, Japan) for the excellent help in the statistical analysis of the data and preparation of the manuscript.

\section{References}

1. Gupta S, Hawker GA, Laporte A, Croxford R and Coyte PC: The economic burden of disabling hip and knee osteoarthritis (OA) from the perspective of individuals living with this condition. Rheumatology 44: 1531-1537, 2005.

2. Yoshimura N, Oka H, Muraki S, et al: Epidemiology of osteoarthritis in Japan. J Jpn Orthop Assoc (In Japanese) 81: 17-21, 2007.

3. Budewalter JA, Stanish WD, Rosier RN, Schenck RC Jr, Dennis DA and Coutts RD: The increasing need for nonoperative treatment of patients with osteoarthritis. Clin Orthop 385: 36-45, 2001.

4. Rashad S, Revell P, Hemmingway A, Low F, Rainsford K and Walker F: Effect of non-steroidal anti-inflammatory drugs on the course of osteoarthritis. Lancet 2: 519-522, 1989 
5. Clayton JJ: Nutraceuticals in the management of osteoarthritis Orthopedics 30: 624-629, 2007.

6. Verbruggen G: Chondroprotective drugs in degenerative joint diseases. Rheumatology 45: 129-138, 2005.

7. Goldberg VM and Buckwalter JA: Hyaluronans in the treatment of osteoarthritis of the knee: evidence for disease-modifying activity. Osteoarthritis Cartilage 13: 216-224, 2005.

8. Petrella RT: Hyaluronic acid for the treatment of knee osteoarthritis: long-term outcomes from a naturalistic primary care experience. Am J Phys Med Rehabil 84: 278-283, 2005.

9. Sun SF, Hsu CW, Hwang CW, Hsu PT, Wang JL, Tsai SL, Chou YJ, Hsu YW, Huang CM and Wang YL: Hyaluronate improves pain, physical function and balance in the geriatric, osteoarthritic knee: a 6-month follow-up study using clinical tests. Osteoarthritis Cartilage 14: 696-701, 2006.

10. Hunter DJ and Hellio Le Graverand-Gastineau M-P: How close are we to having structure-modifying drugs available? Rheum Dis Clin N Am 34: 789-802, 2008.

11. Gossec L and Dougados M: Intra-articular treatments in osteoarthritis: from the symptomatic to the structure modifying. Ann Rheum Dis 63: 478-482, 2004.

12. Patti AM, Gabriele A, Vulcano A, Ramieri MT and Della Rocca C: Effect of hyaluronic acid on human chondrocytes cell lines from articular cartilage. Tissue Cell 33: 294-300, 2001.

13. Akmal M, Siingh A, Anand A, Kesani A, Aslam N, Goodship A and Bentley G: The effects of hyaluronic acid on articular chondrocytes. J Bone Joint Surg Br 87: 1143-1149, 2005.

14. Adams ME, Lussier AJ and Peyron JG: A risk-benefit assessment of injections of hyaluronan and its derivatives in the treatment of knee osteoarthritis. Drug Saf 23: 115-130, 2000.

15. Huang SL, Ling PX and Zhang TM: Oral absorption of hyaluronic acid and phospholipids complexes in rats. World J Gastroenterol 13: 945-949, 2007.

16. Hatayama T, Nagano $M$ and Yamaguchi N, Kumagai $S$ and Ohnuki K: The effect of a supplement on knee pain and discomfort evaluated by visual analog scale (VAS): a randomized, double-blind, placebo-controlled study (in Japanese). Kenkoshien 10: 13-17,2008.

17. Ravaud P, Giraudean B, Auleley GR, Drape JL, Rousselin B, Paolozzi L, Chastang C and Dougados M: Variability in knee radiographing: implication for definition of radiological progression in medical knee osteoarthritis. Ann Rheum Dis 57: 624-629, 1998.

18. Vignon E, Garnero P, Delmas P, Avouac B, Bettica P, Boers M, Ehrich E, MacKillop N, Rovati L, Serni U, Spector T and Reginster JY: Recommendations for the registiation of drugs used in the treatment of osteoarthritis: an update on biochemical markers. Osteoarthritis Cartilage 9: 289-293, 2001.

19. Garnero P and Delmas PD: Biomarkers in osteoarthritis. Nature Clin Pract Rheumatol 3: 346-356, 2007.
20. Poole AR, Ionescu M, Fitzcharles MA and Billinghurst RC: The assessment of cartilage degradation in vivo: development of an immunoassay for the measurement of in body fluids of type II collagen cleared by collagenases. J Immunol Methods 294: 145-153, 2004

21. Garnero P, Ayral X, Rousseau J-C, Christgau S, Sandell LJ, Dougados $\mathrm{M}$ and Delmas P: Uncoupling of type II collagen synthesis and degradation predicts progression of joint damage in patients with knee osteoarthritis. Arthritis Rheum 46: 2613-2624, 2002.

22. Cahue S, Sharma L, Dunlop D, Ionescu M, Song J, Lobanok T, King L and Poole AR: The ratio of type II collagen breakdown to synthesis and its relationship with the progression of knee osteoarthritis. Osteoarthritis Cartilage 15: 819-823, 2007.

23. Sato T and Iwaso $\mathrm{H}$ : An effectiveness study of hyaluronic acid [Hyabest $\left.{ }^{\circledR}(\mathrm{J})\right]$ in the treatment of osteoarthritis of the knee on patients in the United States. J New Rem Clin 58: 249-256, 2009.

24. Kalman DS, Heimer M, Valdeon A, Schwartz H and Sheldon E: Effect of a natural extract of chicken combs with a high content of hyaluronic acid (Hyal-Joint ${ }^{\circledR}$ ) on pain relief and quality of life in subjects with knee osteoarthritis: a pilot randomized doubleblind placebo-controlled trial. Nutrition J 7: 3, 2008.

25. Fransen M, McConnell S and Bell M: Exercise for osteoarthritis of the hip or knee. Cochrane Database Syst Rev (CD 004286), 2003.

26. Roos EM and Dahlberg L: Positive effects of moderate exercise on glycosaminoglycan content in knee cartilage: a four-month, randomized, controlled trial in patients at risk of osteoarthritis. Arthritis Rheum 52: 3507-3514, 2005

27. Christgau S, Henrotin Y, Tankó LB, Rovati LC, Collette J, Bruyere O, Deroisy R and Reginster JY: Osteoarthritic patients with high cartilage turnover show increased responsiveness to the cartilage protecting effects of glucosamine sulfate. Clin Exp Rheumatol 22: 36-42, 2004.

28. Cibere J, Thorne A, Kopec JA, Singer J, Canvin J, Robinson DB, Pope J, Hong P, Grant E, Lobanok T, Ionescu M, Poole AR and Esdaile JM: Glucosamine sulfate and cartilage type II collagen degradation in patients with knee osteoarthritis. J Rheumatol 32: 896-902, 2005

29. Mazières B, Hucher M, Zaïm M and Garnero P: Effect of chondroitin sulfate in symptomatic knee osteoarthritis: a multicentre, randomised, double-blind, placebo-controlled study. Ann Rheum Dis 66: 639-645, 2007.

30. Bay-Jensen AC, Andersen TL, Charni-Ben Tabassi N, Kristensen PW, Kjaersgaard-Andersen P, Sandell L, Garnero P and Delaissé JM: Biochemical markers of type II collagen breakdown and synthesis are positioned at specific sites in human osteoarthritic knee cartilage. Osteoarthritis Cartilage 16: 615-623, 2008. 